\title{
Nanotechnology and Development of Oral Insulin
}

\author{
Nahid Sarlak* and Fatemeh Sadat Mousavizadeh \\ Department of Chemistry, Faculty of Science, Lorestan University, Iran \\ *Corresponding author: Nahid Sarlak, Department of Chemistry, Faculty of Science, Lorestan University, Iran
}

\begin{tabular}{|c|c|}
\hline ARTICLE INFO & ABSTRACT \\
\hline Received: 㓞 November 25, 2019 & Wide researches have been done to investigate the oral delivery system of insulin for \\
\hline Published: 㓞 December 03, 2019 & $\begin{array}{l}\text { the diabetes' treatment. Developments in nanotechnology have brought us ever closer } \\
\text { to this purpose. The current review focuses on the various barriers existing in the way }\end{array}$ \\
\hline
\end{tabular}

Mousavizadeh. Nanotechnology and Development of Oral Insulin. Biomed J Sci \& Tech Res 23(3)-2019. BJSTR. MS.ID.003911.

Keywords: Insulin; Oral Delivery; Diabetes; Nanoparticles; Nanomedicine

Abbreviations: GI: Gastrointestinal; CS: Chitosan

\section{Introduction}

Nanomedicine performance includes monitoring, controlling, construction, repair, protection, and enhancement of human biological organizations at the molecular levels; using nanodevices and nanostructures that operate at a single-cell scale is to reach the medical benefits. The most important application of nanotechnology in medicine is that it can target selected areas thus it increases the efficiency of drugs and reduces their side effects. Nanotechnology or nanomedicine is being exploited widely in research and development of medicine [1]. Diabetes mellitus explains a metabolic disturbance of several etiology defined by persistent hyperglycemia due to disorders of carbohydrate, lipid and protein metabolism which occur from imperfection of insulin secretion, insulin action, or both. The effects of diabetes mellitus involve long-term destruction, dysfunction and failure of many organs [2]. Diabetes is one of the major suffering diseases of modern society and yet, diabetic patients inject insulin directly into their blood-vessels in order to control their blood-sugar levels. Problems and difficulties of insulin injection have produced many efforts to explore an alternative for insulin therapy, including oral, pulmonary, and nasal delivery of insulin. Stomach acid destroys protein-based drugs such as Insulin and makes oral insulin consumption wasteful. Therefore, the desired results could be achieved by encapsulating insulin molecules in polymeric nanoparticles [3].

\section{Oral Delivery and Its Problems}

Oral delivery of drugs is widely preferred because of its easy usage and the more comfortable condition in which patient takes the drug painless. The success of improved oral insulin is very helpful for the treatment of diabetes mellitus to prevail over the problem of daily subcutaneous injections [4]. Particles in the gastrointestinal (GI) area could be absorbed by several sites and mechanisms. The effective factors in absorption are the particle size, surface charge or hydrophobicity, concentration and any targeting mechanisms on the particle that would press out vicinity to determined sites in the GI tract [5]. The duty of the GI system includes the digestion and absorption of nutrients and being as a defense barrier to pathogenic microorganisms and toxins [6]. So, manifold challenges exist for oral delivery of the drugs. Main barriers to oral delivery of peptide- and protein-based drugs include the chemical degradation (extreme $\mathrm{pH}$ conditions, proteolysis enzymes) and the physical barrier (Mucus layer and Intestinal epithelium) in GI tract [6,7]. Thus, insulin should be enveloped in a matrix to keep it safe from gastric enzymes. This is reached by encapsulating the insulin molecules in polymeric nanoparticles. Insulin was loaded in different nanoparticles as oral delivery structure, such as natural polymeric nanoparticles [8], synthetic polymeric nanoparticles [9], solid lipid 
nanoparticles [10], liposomes [11], and nano emulsions [12], as well as the inorganic nanoparticles [9]. These nanoscale delivery structures provide a suitable path for insulin delivery. Compared to other nanoparticles, the natural polymeric nanoparticles presented higher biocompatibility and biodegradability, better storage, greater safety and physiological stability [13].

\section{Most Important Insulin Carrier}

Chitosan Production of pharmaceutically active proteins, such as insulin, has become possible. A major barrier to the absorption of hydrophilic drugs is the intestinal epithelium, as they cannot diffuse across epithelial cells through lipid-bilayer cell membranes to the bloodstream. A versatility of intestinal permeation enhancers including chitosan (CS) have been used in order to absorb the hydrophilic macromolecules. Chitosan is a linear polysaccharide derived from chitin, have desirable physicochemical properties, such as biodegradability, non-toxicity, good muco adhesion, abundant renewable sources and low cost [14]. Chitosan, as the unique cationic polysaccharide, could interact with polyanions leading to the spontaneous formation of nanoparticles, which is generally referred as ionic gelation or polyelectrolyte complexation technique. Most convenient chitosan-based nanoparticles are prepared by letting chitosan and its derivatives to react with various anionic polyelectrolytes include tripolyphosphate (TPP) [15], alginate [16], poly (g-glutamic acid) [17] and lecithin [18]. Five general protocols that show the preparation of chitosan-based nanoparticles for oral insulin delivery, are summarized in Figure 1 [19].

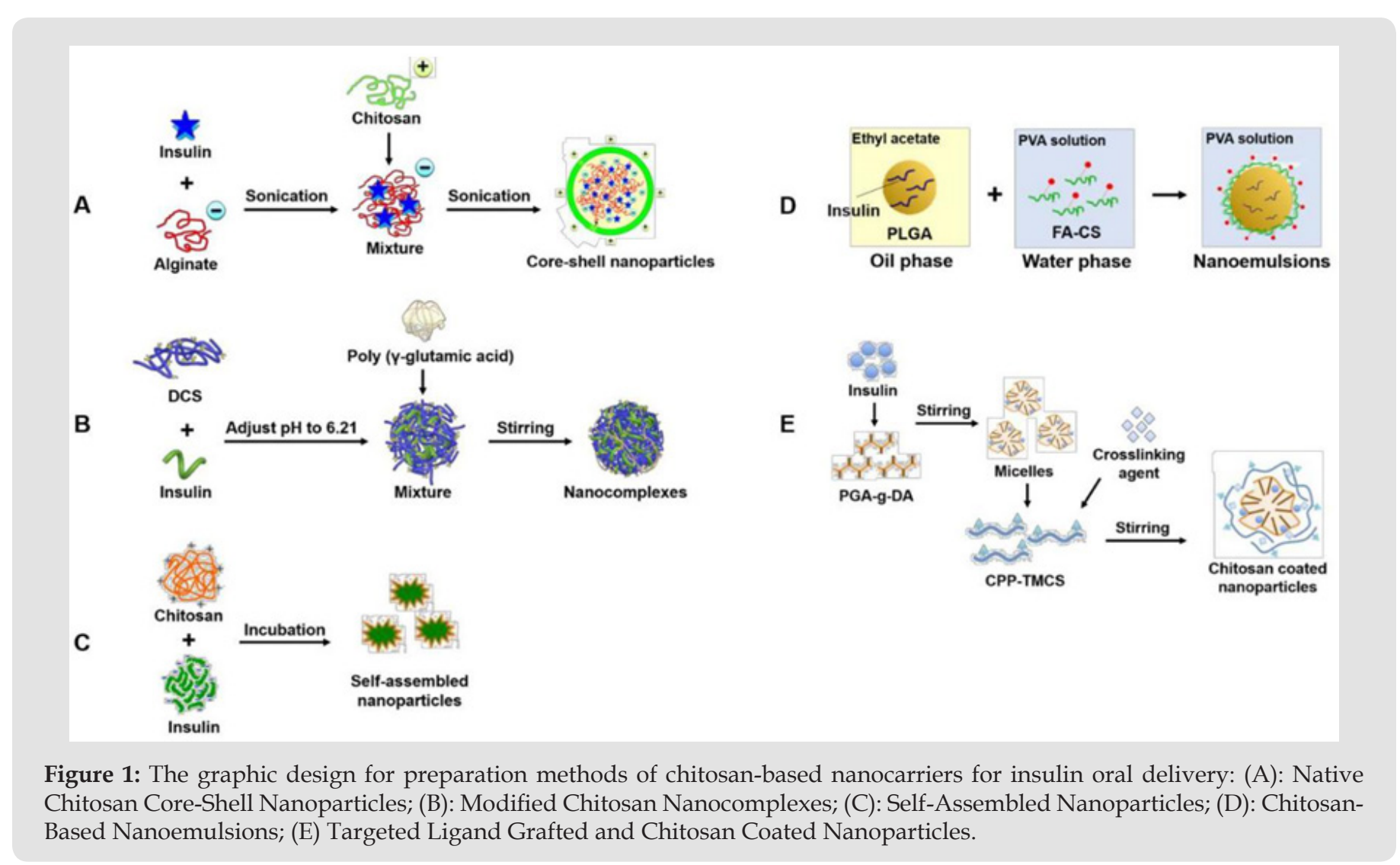

Alginate extracted from brown seaweed and is a water-soluble anionic polysaccharide, including alternating blocks of (1-4)-linked $\beta$-D-mannuronic acid (M) and $\alpha$-L-guluronic acid (G) residues [20]. Alginate has obtained notable interests in oral delivery of insulin, because of some desirable attributes, such as biodegradability, biocompatibility, low immunogenicity, good mucoadhesion, and non-toxicity. Diverse alginate-based nanoparticles have been synthesized by ionic gelation or polyelectrolyte complexation. Asunder from nanotechnology, other strategies, such as $\mathrm{pH}$ responsive alginate/ $\kappa$-carrageenan composite hydrogel beads [21], colloidosomes based on chitosan-coated alginate particles [22], and hydrogel microparticles [23], have also been investigated to elevate the oral insulin administration using alginate-based delivery methods.

\section{Conclusion}

Nanotechnology has presented a helpful substrate for insulin carriers. As expecting, there have been new researches and explorations of potential NPs to provide insulin orally; these formulations are being modified continually so the future of oral insulin seems promising.

\section{References}

1. Zarbin MA, Montemagno C, Leary JF, Ritch R (2010) Nanotechnology in ophthalmology. Can J Ophthalmol 45(5): 457-476. 
2. Alberti KG, Zimmet PZ (1998) Definition, diagnosis and classification of diabetes mellitus and its complications. Part 1: diagnosis and classification of diabetes mellitus provisional report of a WHO consultation. Diabetic medicine 15(7): 539-553.

3. Kahn B, Flier J (2000) Obesity and insulin resistance. J Clin Invest 106(4): 473-481.

4. Plapied L, Duhem N, des Rieux A, Préat V (2011) Fate of polymeric nanocarriers for oral drug delivery. Curr Opin Colloid Interface Sci 16(3): 228-237.

5. O'Hagan DT (1996) The intestinal uptake of particles and the implications for drug and antigen delivery. J Anat 189: 477-482.

6. Chen MC, Sonaje K, Chen KJ, Sung HW (2011) A review of the prospects for polymeric nanoparticle platforms in oral insulin delivery. Biomaterials 32(36): 9826-9838.

7. Walker RI, Owen RL (1990) Intestinal barriers to bacteria and their toxins. Annu Rev Med 41: 393-400.

8. Sarmento B, Ribeiro A, Veiga F, Sampaio P, Neufeld R, et al. (2007) Alginate/Chitosan Nanoparticles are Effective for Oral Insulin Delivery. Pharm Res 24(12): 2198-2206.

9. Joshi HM, Bhumkar DR, Joshi K, Pokharkar V, Sastry M (2006) Gold Nanoparticles as Carriers for Efficient Transmucosal Insulin Delivery. Langmuir 22(1): 300-305.

10. Sarmento B, Martins S, Ferreira D, Souto EB (2007) Oral insulin delivery by means of solid lipid nanoparticles. Int J Nanomedicine 2(4): 743-749.

11. Niu M, Lu Y, Hovgaard L, Guan P, Tan Y, et al. (2012) Hypoglycemic activity and oral bioavailability of insulin-loaded liposomes containing bile salts in rats: the effect of cholate type, particle size and administered dose. Eur J Pharm Biopharm 81(2): 265-272.

12. Li X, Qi J, Xie Y, Zhang X, Hu S, et al. (2013) Nanoemulsions coated with alginate/chitosan as oral insulin delivery systems: preparation, characterization, and hypoglycemic effect in rats. Int J Nanomedicine 8(1): 23-32.

ISSN: 2574-1241

DOI: 10.26717/BJSTR.2019.23.003911

Nahid Sarlak. Biomed J Sci \& Tech Res

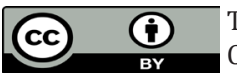

This work is licensed under Creative Commons Attribution 4.0 License

Submission Link: https://biomedres.us/submit-manuscript.php
13. Nagavarma B, Yadav HK, Ayaz A, Vasudha LS, Shivakumar HG (2012) Different techniques for preparation of polymeric nanoparticles. Asian J Pharm Clin Res 5(3): 16-23.

14. Hu Q, Luo Y (2016) Polyphenol-chitosan conjugates: Synthesis, characterization and applications. Carbohydr Polym 151: 624-639.

15. Devasia S, Sukumaran M, Kumar SJ (2017) Development of chitosan-Tri polyphosphate nanomaterials for oral delivery of insulin. J Polym Mater 34: 75-89.

16. Mansourpour M, Mahjub R, Amini M, Ostad SN, Shamsa ES, et al. (2015) Development of acid-resistant alginate/trimethyl chitosan nanoparticles containing cationic $\beta$-cyclodextrin polymers for insulin oral delivery. AAPS Pharm SciTech 16(4): 952-962.

17. Fan W, Xia D, Zhu Q Li X, He S, et al. (2018) Functional nanoparticles exploit the bile acid pathway to overcome multiple barriers of the intestinal epithelium for oral insulin delivery. Biomaterials 151: 13-23.

18. Liu L, Zhou C, Xia X, Liu Y (2016) Self-assembled lecithin/chitosan nanoparticles for oral insulin delivery: preparation and functional evaluation. Int J Nanomedicine 11: 761-769.

19. Hu Q Luo Y (2018) Recent advances of polysaccharide-based nanoparticles for oral insulin delivery. Int J Biol Macromol 120(Pt A): 775-782.

20. Yang JS, Xie YJ, He W (2011) Research progress on chemical modification of alginate. Carbohydr Polym 84: 33-39.

21. Lim HP, Ooi CW, Tey BT, Chan ES (2017) Controlled delivery of oral insulin aspart using $\mathrm{pH}$-responsive alginate/ $\kappa$-carrageenan composite hydrogel beads. React Funct Polym 120: 20-29.

22. Nan F, Wu J, Qi F, Fan Q, Ma G, et al. (2014) Preparation of uniformsized colloidosomes based on chitosan-coated alginate particles and its application for oral insulin delivery. J Mater Chem 2: 7403-7409.

23. Déat Lainé E, Hoffart V, Garrait G, Jarrige JF, Cardot JM, et al. (2013) Efficacy of mucoadhesive hydrogel microparticles of whey protein and alginate for oral insulin delivery. Pharm Res 30(3): 721-734.

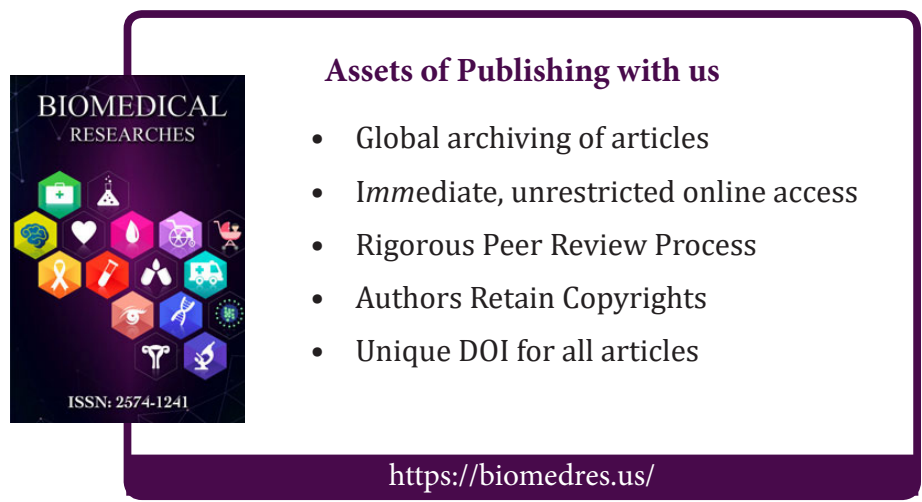

